\title{
EDUCAÇÃO AMBIENTAL: O SOLO COMO RECURSO DIDÁTICO NA PRODUÇÃO DE TINTAS E PINTURAS
}

\author{
Claudemir Fonseca Gonçalves ${ }^{(a)}$, Nádia Rosania Reis de Oliveira ${ }^{(b)}$ \\ ${ }^{(a)}$ Graduado no Curso de Geografia, Universidade do Estado do Amazonas, E-Mail: \\ Claudemirgeouea855@gmail.com \\ ${ }^{(b)}$ Graduado(a) no Curso de Geografia, Universidade, do Estado do Amazonas, E-mail: nadiaoliveira530@gmail.com
}

\section{Eixo: GEOGRAFIA FÍSICA: CURRICULO, FORMAÇÃO E PRÁTICAS DE ENSINO}

\begin{abstract}
Resumo
O presente trabalho tem como objetivo principal compreender a importância do estudo dos solos e sua utilização como recurso didático no ensino de Geografia a partir da oficina pedagógica intitulada, Educação Ambiental: o solo como recurso didático na produção de tintas e pinturas. $\mathrm{O}$ público alvo foram os alunos do sétimo ano da Escola Geny Bentes de Jesus, da rede estadual de ensino do Município de Parintins- AM, por meio do Programa Institucional de Bolsas de Iniciação à Docência- PIBID, Coordenação de Aperfeiçoamento de Pessoal de nível Superior- CAPES, Universidade do Estado do Amazonas- UEA. Foram ministradas aulas teóricas sobre o tema, em seguida, ocorreu a segunda etapa em formato de oficina pedagógica onde os alunos produziram as tintas com as diferentes cores de solo, ilustrando as telas com desenhos selecionados pelos Pibidianos. Os alunos que estiveram envolvidos na oficina demonstraram um interesse significativo para que a oficina tivesse êxito a partir das pinturas realizadas. A presente oficina teve o intuito de promover nos alunos o despertar para a construção do conhecimento interdisciplinar, permitindo maior interesse e participação nas aulas de geografia.
\end{abstract}

Palavras chave: PIBID, Oficinas pedagógicas, Educação Ambiental, Tintas de solo.

\section{Introdução}

O presente relato de experiência tem como objetivo mostrar o resultado de uma oficina pedagógica realizada pelos pibidianos do curso de Geografia da Universidade do Estado do Amazonas, como bolsistas da CAPES- Coordenação de Aperfeiçoamento de Pessoal de nível Superior através do Programa Institucional de Bolsa de Iniciação à Docência - PIBID. Esse trabalho se deu em função da necessidade de aprofundar os estudos de cunho ambiental nas aulas de geografia possibilitando ao educando a percepção do papel da relação sociedade-natureza proporcionando nos mesmos maior interesse pela disciplina a partir do exercício das práticas pedagógicas relacionadas as questões ambientais de maneira educativa e reflexiva, assim como nas relações sócios espaciais, geopolíticas e produtivas dos "lugares" com o mundo por eles percebido e concebido. Dessa forma o trabalho faz uma análise dos principais assuntos que nortearam a execução da referida oficina: PIBID: No contexto escolar ensino aprendizagem de Geografia, as ações do PIBID têm o objetivo de propor atividades diferenciadas aos alunos, haja vista que à escola também é beneficiada com estas atividades. Assim quanto mais próximo os acadêmicos estiverem 
com a e educação básica, haverá um contínuo contato de saberes e experiências compartilhadas que contribuirão para a formação de bons alunos e professore; Oficinas pedagógicas, é através das oficinas que os alunos são mais participativos, interagem o tempo todo e se mostram interessados no que está sendo repassado nas atividades proposta em sala de aula; o ensino de solos, $\mathrm{O}$ estudo de solos tem como objetivo, permitir aos alunos o conhecimento sobre a importância desse recurso natural, visto que e dada pouca ênfase sobre esse estudo no ensino fundamental, especialmente em se tratando do solo como instrumento pedagógico numa perspectiva integral que comtemple de certa forma todos os elementos da natureza assim como suas relações.

Com o adventos das inovações tecnológicas, materializada no espaço os saberes são construídos diariamente, nesse contexto ser professor na atualidade e de extrema importância para a sociedade, responsável pela construção de conhecimentos e formação de cidadãos críticos, requerendo qualificações pedagógicas e acadêmicas além de uma formação humana para atender as necessidades do mundo atual.

\section{PIBID: No contexto escolar ensino aprendizagem de Geografia}

Atualmente há um grande distanciamento entre a escola e a universidade, o PIBID- Programa Institucional de Bolsas de Iniciação a Docência é capaz de fazer essa integração entre estas duas importantes instituições proporcionando melhor formação aos graduandos de licenciatura e contribuindo com o ensino nas escolas públicas. Estas ligações entre o meio escolar e as universidades possibilitam aos alunos da licenciatura aprender a compreender a escola, e consequentemente propor soluções, questionamentos e ideias para melhorar o ambiente escolar.

As ações do PIBID têm o objetivo de propor atividades diferenciadas aos alunos à escola também é beneficiada com estas atividades. Assim quanto mais próximo ensino superior e educação básica estiverem, haverá um contínuo contato de saberes e experiências compartilhadas que contribuirão para a formação de futuros professores, auxiliarão em novas metodologias de trabalho para professores da educação básica e também na formação de alunos.

\section{Metodologia}

Para a realização da oficina utilizou-se pesquisas bibliográficas em livros, revista e sites da internet acerca do tema proposto. Aulas teóricas sobre o conteúdo em seguida ocorreu a parte pratica da oficina onde foram construídas telas de madeira medindo 30 x $20 \mathrm{~cm}$, utilizando os seguintes matérias: ripetas de $2 \mathrm{~cm}$ de largura, pano saca, copos descartáveis, colheres descartáveis, tachinhas, tesoura, garrafas descartáveis, cola branca, água, solos do tipo: latossolo: amarelo alaranjado, argissolo, horizonte A (matéria orgânica) 
para a fabricação da Tinta. Ressaltando que esses solos foram primeiramente triturado, peneirados e separado cada tipo de solo num recipiente.

Também foram utilizados equipamentos de apoio tecnológicos como: notebook, data show. Procurando contribuir para o bom desenvolvimento dos alunos nas das atividades em sala de aula.

\section{Oficina pedagógica e suas contribuições para o ensino da geografia}

A oficina pedagógica intitulada: "Educação Ambiental tendo o solo como material Didático, realizou-se nas turmas do $7^{\circ}$ ano, do turno vespertino juntamente com os professores de geografia da Escola Estadual Genny Bentes de Jesus, a através de aulas expositivas utilizando os recursos didáticos necessários para uma aula dinâmica e de fácil compreensão por parte dos alunos para posteriormente ser executada a oficina na pratica com os alunos.

Figuras 1 e 2: aula teórica nas turmas do $7^{\circ}$ ano

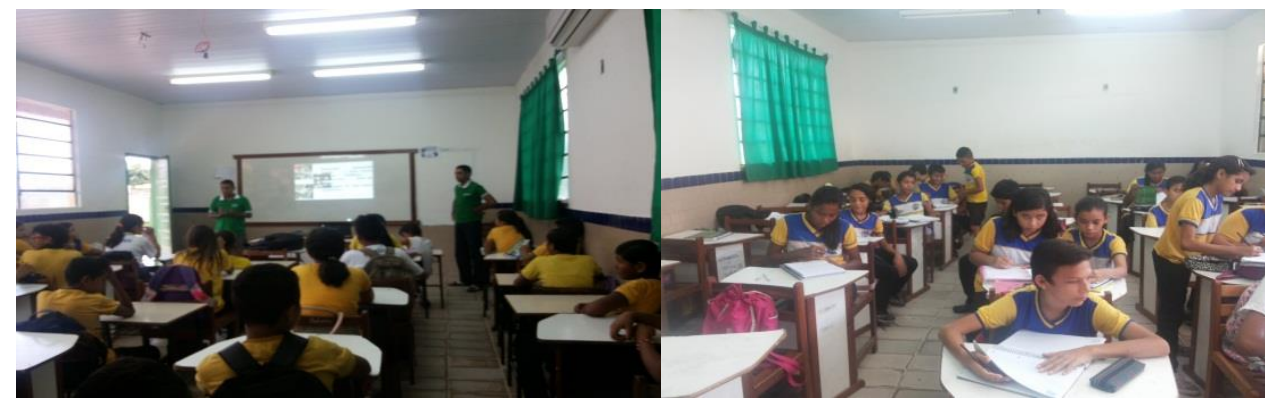

Fonte: Oliveira/2016

Dessa forma, (CAVALCANTI, 2002, p.11) aponta que: "tem procurado pensar seu papel nessa sociedade em mudança, indicando novos conteúdos, reafirmando outros, reatualizando alguns outros." Diante disso as oficinas pedagógicas são de grande importância para o ensino de Geografia, pois quando realizadas no âmbito escolar, acaba facilitando o aprendizado do aluno. No terceiro momento realizou-se a oficina onde todos os alunos reuniram-se em um espaço do ambiente escolar para colocar em pratica a oficina, segundo Vieira et al (2002):

$\mathrm{Na}$ oficina surge um novo tipo de comunicação entre professores e alunos. É formada uma equipe de trabalho, onde cada um contribui com sua experiência. O professor é dirigente, mas também aprendiz. Cabe a ele diagnosticar o que cada participante sabe e promover o ir além do imediato. (p.17). 
XVII Simpósio Brasileiro

de Geografia Fisica Aplicada

I Congresso Nacional

de Geografia Física
OS DESAFIOS DA GEOGRAFIA FÍSICA NA FRONTEIRA DO CONHECIMENTO

Instituto de Geociências - Unicamp

Campinas - SP

28 de Junho à 02 de Julho de 2017

Figura 6: pintura em tecido

Figura 5: alunos na pratica da oficina

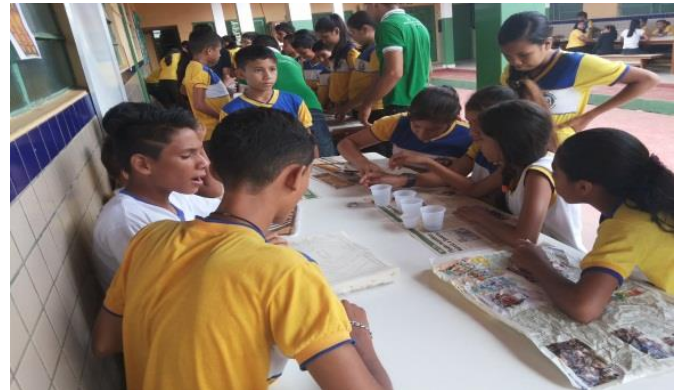

Fonte: Oliveira/2016

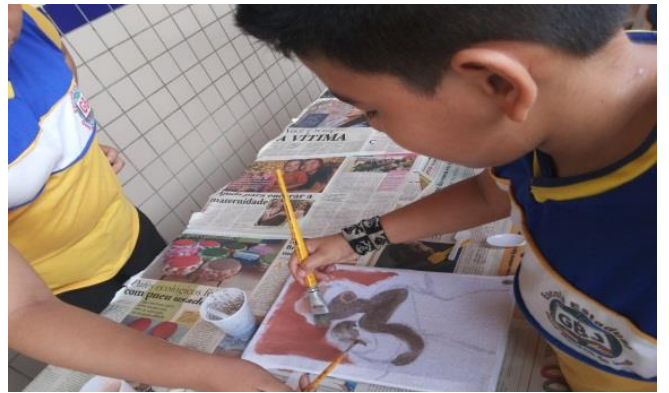

Fonte: Oliveira/2016

Com as Cores do solo se produz material didático de fácil manejo, mais baratos e sustentáveis do ponto de vista ambiental. Para produção das tintas utiliza-se mistura de água, cola branca. Constatamos que a tinta à base de solo é de suma para o processo de ensino aprendizagem nas aulas de Geografia assim como a importância da educação ambiental na sala de aula, podendo relacionar a geografia com o meio ambiente.

Observamos que os alunos envolvidos na oficina demonstraram interesse significativo para que a oficina tivesse êxito assim como todos que se envolveram direta e indiretamente, ou seja, a teoria foi comprovada na prática visto que a oficina muito proveitosa para os Pibidianos alunos e professores mostrando os resultados a partir das pinturas realizadas salientando que todas as telas serão utilizadas na amostra de painéis da escola.

Portanto é notório perceber que é através das oficinas os alunos são mais participativos, interagem o tempo todo e se mostram interessados no que está sendo ilustrado nas atividades proposta em sala de aula.

\section{O ensino de solos}

O ensino de solos tem como objetivo, possibilitar aos alunos e professores um estudo unitário, visto que e dada pouca ênfase sobre esse estudo no ensino fundamental, especialmente em se tratando do solo como instrumento pedagógico numa perspectiva integral que comtemple de certa forma todos os elementos da natureza assim como suas relações.

A presente oficina sobre o uso do solo na fabricação de tintas serviu para fortalecer o conhecimento sobre o uso desse recurso e a importância de sua conservação enquanto recurso natural indispensável à existência das diversas formas de vida. Com isso verificou-se também a necessidade e estudo da origem dos solos por parte dos acadêmicos no intuito de capacita-los para a aplicação da oficina em outros educandários no contexto do ensino de geografia o ensino de solos por abordar uma visão integrada da sociedade e natureza, considerando o objeto de estudo o espaço geográfico e suas relações, não somente do homem com a natureza, mas também com outras ciências. 


\section{OS DESAFIOS DA GEOGRAFIA FÍSICA NA FRONTEIRA DO CONHECIMENTO \\ Instituto de Geociências - Unicamp \\ Campinas - SP \\ 28 de Junho à 02 de Julho de 2017}

Dessa forma o solo deve ser visto assim como outros elementos, como um recurso coletivo sendo este um elemento essencial à vida, integrante do sistema ambiental, sobre essa concepção segundo Chistofoletti, (2007), salienta que "a ciência sistêmica demonstra que os sistemas não podem ser compreendidos através das partes, pois estas não são Propriedades intrínsecas, mas só podem ser entendidas dentro do todo maior".

Nesse contexto o meio ambiente e o resultado da interação de diversos elementos e seus componentes. Diante disso a temática ambiental dentro do espaço escolar permite que os alunos e professores tenham um conhecimento, mas aprofundado do funcionamento do meio ambiente e sua totalidade. Dessa forma é importante destacar os problemas ambientais aos quais agrava a qualidade do solo, implicando diretamente na diminuição de sua fertilidade e capacidade de retenção de água, afetando no crescimento das plantas, muitos desses citados estão relacionados às erosões sobre essa perspectiva sedimentos são removidas de várias encostas, de diversas maneiras, se depositando nas áreas mais deprimidas e nos rios, lagos, baias e reservatórios, causando assoreamento e poluição desses corpos líquidos. (GUERRA E MENDONÇA, 2007, p. 225). Além disso, existe o agravamento decorrente de poluição urbana ocasionada pelo acumulo de lixos que são jogados sobre a superfície, nas áreas rurais a contaminação se dá ainda pelo uso indevido de agrotóxicos nas monoculturas, outros fatores como queimadas e desmatamentos são exemplos de problemas ambientais que contribuem para a deterioração dos solos.

\section{Considerações finais}

A oficina apresentada e uma proposta de ensino que tem o objetivo de fornecer aos alunos e professores novas possibilidades de ensino que busquem dinamizar e despertar o interesse dos alunos na disciplina de Geografia. Com isso o ensino de solos atrelados a educação ambiental, volta-se ao contexto da formação da cidadania e experiência vivida e da participação coletiva na construção de uma consciência ambiental. Contudo, atentar para uma forma de levar o educando a ser participativo, criativo e crítico é uma das funções do educador na escola, mediando conhecimento e mostrando ao aluno sua capacidade de desenvolver seu cognitivo, deixando as aulas mais harmoniosas tendo uma interação com a escola, professor e aluno são algo fundamental na educação contemporânea.

Portanto a presente oficina teve o intuito de promover nos alunos o despertar para a construção do conhecimento interdisciplinar, permitindo maior interesse e participação dos alunos nos conteúdo das aulas de geografia, contribuindo na formação de cidadãos ativos e comprometidos com processo de ensino.

\section{Agradecimentos}




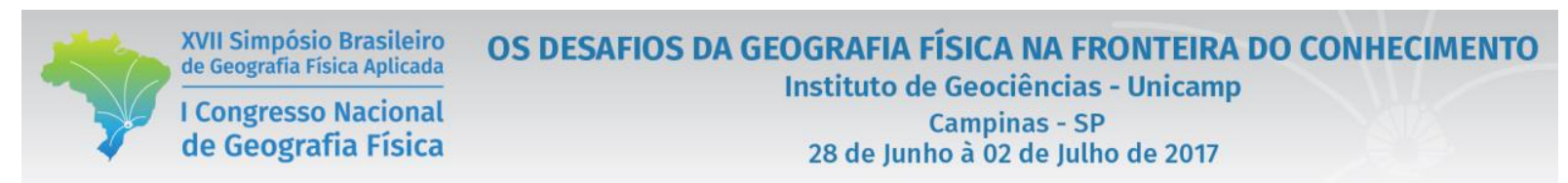

À CAPES que nos oportunizou com as bolsas de docência para atuar no PIBID, contribuindo para nossa formação de futuros docentes.

\section{Bibliografia}

CAVALCANTI, Lana de Souza. Geografia e prática de ensino. Goiânia: Alternativa, 2002.

CHRISTOFOLETTI, A. L. H. Sistemas dinâmicos: as abordagens da teoria do caos e da geometria fractal em geografia; GUERRA, A. J. T.; MENDONÇA, J. K. S. Erosão dos solos e a questão ambiental; In: VITTE, A. C.; GUERRA, A. J. T. Reflexões sobre a geografia física no Brasil. 2ed. Rio de Janeiro: Bertrand, 2007.

VIEIRA, Elaine, VALQUIND, Lea. "Oficinas de Ensino: O quê? Por quê? Como?". $4^{\circ}$ ed. Porto Alegre. EDIPUCRS, 2002. 